Journal of Qualitative Criminal Justice \& Criminology

\title{
Book Review | Qualitative Research in Action: A Canadian Primer
}

Deborah Landry ${ }^{1}$

${ }^{1}$ University of Ottawa

Published on: Apr 01, 2013

DOI: 10.21428/88de04al.fd3fc79b

License: Creative Commons Attribution 4.0 International License(CC-BY 4.0). 
Deborah K. van Den Hoonaard. Qualitative Research in Action: A Canadian Primer. Oxford University Press, 2012; 210 pp.; ISBN: 9780195439199.

Dr. Deborah Van Den Hoonaard has made a distinguished career of applying qualitative methodologies to uncover the rich everyday experiences of marginal populations. Professor Van Den Hoonaard holds a prestigious position as Canada Research Chair in Qualitative Analysis, garnering the respect of her peers for her fieldwork. The savvy experience of a seasoned field researcher unfolds easily in this guidebook, which feels more like a documentary than a methodology textbook. Nodding to the ethnographic traditions of the Chicago School and McGill University (the Canadian version of the Chicago School), her engagement with contemporary approaches is couched in an informed historical context; new scholars are invited to continue the important work of getting the seats of their pants dirty (to paraphrase Robert Park). Given the trend toward Orthodox methodologies that has arguably taken place in the discipline of criminology and criminal justice since the 1980 s, I offer that this book stands as an important contribution to renewing interest in the creation of knowledge about marginalized populations through qualitative research methods.

If you are searching for a book that outlines rigid steps for analyzing data, this is probably not the book for you; regardless, the primer on qualitative approaches is a valuable resource for a contemporary research methods undergraduate syllabus and a supplementary text for graduate level methodological seminars. Written intuitively to the needs of the classroom, the author introduces the reader to an extensive scope of recent literature. In an effort to encourage methods that respond to the contemporary mass media world we negotiate, the book devotes a chapter to introducing new directions in methodology, such as ethnodrama, virtual ethnography, and visual sociology (which, I suggest, is typically misplaced under the heading of content analysis in most other methodology resources).

The book is logically organized into ten topical chapters, which fits easily into a standard single semester undergraduate course. It provides a well paced guide for those who teach using independent classroom-sized research projects that develop over the course of three to four months. For courses that extend into two semesters, instructors can readily augment the book with original research referenced in the book. Each section suggests Learning Objectives, directing readers as they work through the material. Questions for Critical Thought concludes each chapter with brainstorming ideas for in-class group work. For example, the discussion on In-Depth Interviewing encourages students to ask each other questions about best and worst classroom experiences, drawing students into curiosities about social structure that is immediately relatable. The chapter devoted to unobtrusive methods inspires students to consider all collective productions as cultural manifestations of social 
order, ready for analysis, including trash! Highlighting the topical work of Dr. Jeff Ferrell (2006), Van Den Hoonaard provides feasible ideas for research opportunities that are immediately accessible.

There are two key qualities of Qualitative Research in Action that qualify it as exceptional methodology book. First, Dr. Van den Hoonaard recognizes the embodied and political context in which research (particularly field research) unfolds. The book offers informed advice and sound techniques that help anxious students maneuver that strange land between proposing research and doing research. The author walks the reader through realistic coding strategies, encouraging one to trust the processes of systematic analysis without fetishizing techniques. New researchers are encouraged to rely on old school systematic coding by hand (in lieu of coding software, at least initially), learning that the process of conceptualization is a skill based on experience working with data, not software tweaking. This is a bold statement, given the publish or perish narrative that seems to characterize the pace of Western academia, a concern most recently raised by Jock Young (2011) by way of C.W Mills. Van Den Hoonaard's reputable approach to slowing down the process of knowledge construction is a timely political statement. Her accomplishments evince the fact that this research strategy is feasible and valuable.

Second, the Canadian focus provides readers (regardless of nationality) an introduction to the global context in which principled research must be negotiated in our mass mediated world. William Van Den Hoonaard (2012), a distinguished scholar in the area of research ethics, authors a chapter that moves the issue of ethics beyond the actuarial concerns of state-specific university ethics boards. Ethics is explained as a principled process of developing a moral compass and authentic relationships with research participants over time. The ethical discussion in this book will benefit all criminology and criminal justice audiences, regardless of nationality.

This text does not provide step by step instructions, which is not the purpose of this text; the guidelines and reflexive scope of possibilities, considerations and concerns for qualitative research provided in the text are impressive given its paperback size of approximately 200 pages. The primer is authored in a welcoming accessible tone, despite communicating an important political message about the need for more reflexive critical analysis that considers the lived realities of marginalized populations. Professor D. Van Den Hoonaard's contribution to the research methods literature has become a staple in my methods courses, as well as the starting book for graduate students I supervise. In sum, it is a politically important and methodologically cogent pearl in a sea of methodology texts.

\section{References}

Ferrell, J. (2006). Empire of scrounge. New York, NY: New York University Press.

Van Den Hoonaard, W. (2011). The seduction of ethics: Transforming the social sciences. Toronto, Canada: University of Toronto Press. 
Young, J. (2010). The criminological imagination. Cambridge, England: Polity Press. 